\title{
Prevalence of Dental Caries and Dental Defects of Enamel in Children Aged 3 to 5 Years-Old from Salvador- BA, Brazil, 2018
}

\section{Tatiana Frederico de Almeida ${ }^{1 *}$, Amanda Luisa Rodrigues de Paiva ${ }^{2}$, Ágatha Larissa do Nascimento dos Anjos' ${ }^{2}$, Maria Beatriz Barreto de Sousa Cabral ${ }^{1}$, Maria Isabel Pereira Vianna ${ }^{1}$ and Maria Cristina Teixeira Cangussu ${ }^{1}$}

${ }^{1}$ Professor in School of Dentistry/UFBA,Rua Araújo Pinho, Salvador,Brazil ${ }^{2}$ Graduate student in School of Dentistry/UFBA, Rua Araújo Pinho, Salvador, Brazil

*Corresponding Author: Tatiana Frederico de Almeida, Professor in School of Dentistry/UFBA, Rua Araújo Pinho, Salvador, Brazil.
Received: March 18, 2020

Published: April 28, 2020

(C) All rights are reserved by Tatiana

Frederico de Almeida., et al.

\begin{abstract}
Objective: To describe the prevalence and severity of dental caries and enamel changes in children aged 3 to 5 years in the city of Salvador, Bahia, Brazil and analyze some factors associated with these changes.

Methodology: This is a cross-sectional study that investigated dental caries and enamel changes (opacity, hypoplasia and fluorosis) in children aged 3 to 5 years, who attended municipal public daycare centers and Family Health Units, in 2018. Descriptive and univariate analyzes were performed, using the chi-square test with $5 \%$ significance, in search of potential associated factors (sociodemographic, white spot and dental calculus) with the investigated problems.

Results: 2788 children were examined, with a mean age of 54 months (SD = 5.8), 50.90\% male and 92.97\% brown/black. The prevalence of caries was $38.38 \%$ and the dmf-t was 1.53; the prevalence of enamel alteration was $10.56 \%$. The highest occurrence of caries was associated with the child's age ( 55 months or more), presence of white spot, dental biofilm and enamel changes ( $p<0.05$ ). Higher prevalence of enamel defects was associated with older age (55 months or more) and with the presence of caries. Children who were examined at public daycare centers had more oral problems than those who were examined at Family Health Units ( $\mathrm{p}$ $<0.05$ ).

Conclusion: Early caries and enamel changes still represent problems to be controlled in the city of Salvador-BA. Preventive oral health strategies must be implemented or reinforced.

Keywords: Epidemiology; Preschool Children; Dental Caries; Dental Enamel Hypoplasia
\end{abstract}

\section{Introduction}

Oral health in childhood is still marked by the presence of caries in a significant population in Brazil. Early childhood caries is defined as caries that affect the primary dentition of children up to the sixth year of life, representing a multifactorial disease [1]. Among the factors associated with this oral health problem stands out: biological and sociodemographic factors, children's behavioral aspects (hygiene habits and diet) and how caregivers act about the health of children at an early age [2].

The occurrence of pain and infection is common to children affected by dental caries, which can affect their development, as well as the quality of life from an individual and family point of view $[3,4]$.
The prevalence of dental caries in Brazil in preschoolers has been studied and monitored over the years. It is known that the severity and extent of tooth decay in children increases proportionally with increasing age. National results from oral health surveys showed that the proportion of individuals free of the disease increased only $6 \%$ at 05 years of age between 2003 and 2010 [5,6]. In the municipality of Salvador (BA), it was observed that $50 \%$ of children at 05 years of age were free of caries in 2005 [7] and in 2015, this percentage had not changed, as revealed by another municipal oral health survey (50.5\%) [8]. The dmf-t index that evaluates the extent of this oral problem also remains high in primary dentition in this age group, both in the country as a whole and among children from Salvador: SB Brazil 2010 revealed a dmf- $t$ at 05 years of age equal to 2.43 and in Salvador-BA, this index was 2.1 in 2015 [8]. 
It is noteworthy that the need for surgical-restorative treatment related to the presence of early caries in this group is high. More than $88 \%$ of the primary teeth of children aged 5 years with a history of caries involvement were decayed in the 2010 national survey and, in Salvador, this percentage is around $90 \%[5,8]$. This fact reveals the need to plan and implement preventive and rehabilitative strategies for oral health more effective in health services, focusing on Brazilian preschoolers.

More recently, changes in tooth enamel, which still occur during its formation, such as opacities, hypoplasia and fluorosis, have been further investigated in primary dentition. However, population studies on this problem in Brazil are still rare [9-11]. The prevalence of enamel changes in the primary dentition varies between $23.9 \%$ and $77.3 \%$ [9-12]. The literature reports that enamel disorders can predispose to dental caries, tooth sensitivity, malocclusion and aesthetic problems in preschoolers [1,9,12]. Its etiology is multifactorial and can be caused by genetic changes and environmental factors, acquired after birth, such as diseases infectious [13].

In this perspective, the aim of this study was to describe the occurrence of early caries and enamel changes in this age group from a survey population, with children living in the twelve health districts of the capital of Bahia, held in 2018. In addition, some factors associated with these oral problems were also investigated, such as some sociodemographic factors, the presence of dental biofilm, among others.

\section{Methodology}

This investigation is an epidemiological cross-sectional study. Data collection was carried out in 2018 in Salvador, capital of the state of Bahia, which is administratively divided into 12 health districts.

A pilot study was first carried out in a public daycare center to evaluate the methodology and the understanding of the instruments. The main study population involved children and their mothers or guardians. Children who participated in the pilot study was not included in the main study.

A multi-stage sampling process was followed to obtain the sample. This was calculated considering $10 \%$ of the prevalence of the event, a standard error of $2.9 \%$. A 95\% confidence interval was used. The sample size was estimated at 941 children. In order to increase the accuracy of the study, a correction factor of 1.5 was used. To satisfy the necessary criteria, the sample size was 1412 individuals. But the sample was increased by $15 \%$ to compensate for possible losses, totaling 1623 children.
It should be noted that the sample distribution was proportional to the total number of children enrolled in municipal public daycare centers in each health district. Nurseries or day care public centers and health units were randomly selected in each of the districts. At the time of oral exams, all children between 36 and 71 months present were evaluated.

During data collection, three Public Health teachers from the Dentistry course at the Federal University of Bahia and another 08 students from the same course were responsible for oral exams and interviews. All of them participated in the training and calibration process. The inter-examiner calibration took place in a public daycare center, with 30 children aged 3 to 5 years being examined by the collection team. The intra-examiner calibration, in turn, was measured during data collection, when $10 \%$ of the exams were repeated after 7 days of the first assessment. The Kappa coefficient and the agreement index were then used (inter and intra-examiner agreement rates equal to or greater than $90 \%$ and Kappa equal to or greater than 0.85 for all evaluated oral conditions).

Dental enamel changes were evaluated based on the criteria defined by the Dental Health, Research and Epidemiology Commission of the World Dental Federation (FDI) [14]. The presence of any changes related to enamel defects according to the FDI criteria was considered to be the presence of enamel alteration during data analysis. Dental caries were assessed according to the criteria proposed by the dmf-t, the same index used in the latest national epidemiological surveys [5,6]. Early caries was considered to be the presence of early caries in every child examined with a dmf-t greater than zero.

The public daycare center and the waiting room of health units were the places where the questionnaire was applied with the mothers or guardians and the children's oral exams were carried out. The children were seated, in an environment with natural light, and the oral exams had the aid of a mirror, a periodontal probe from the World Health Organization (WHO) and personal protective equipment.

The questionnaire aimed at mothers or guardians of children was self-administered and contained child identification data and sociodemographic data: sex (male/female), age (36-55 months/ over 55 months), skin color (white/others).

The presence of dental caries and enamel defects were the two dependent variables considered in the exploratory (univariate) analyzes performed. Sociodemographic conditions, such as the child's age, sex, skin color, as well as the occurrence of oral health problems, were assessed as independent variables. 
The data were entered into EXCEL[15] and analyzed in STATA[16]. Descriptive analyzes of sociodemographic conditions and investigated oral conditions were carried out. Pearson's chi-square test was used in exploratory analyzes of potential factors associated with early caries and tooth enamel defects, observing a significance level of $5 \%$.

The work was approved by the Research Ethics Committee of the School of Dentistry of the Federal University of Bahia/Brazil (CAAE78351317.0.0000.5024).

\section{Results}

About 2.788 children participated in the study (between 36 and 71 months of age; mean age of 54 months). In table 1 , we observed that most children were 55 months old or older $(54.20 \%)$, were male $(50.90 \%)$ and had black skin color (92.97\%). Most of them were examined in public municipal daycare centers $(78.16 \%)$ (Table1).

The prevalence of incipient lesions of dental caries was $9.97 \%$ and of early caries $38.38 \%$; $56.28 \%$ of preschoolers had dental biofilm, however, most children did not have calculus (95.12\%). In the case of dental enamel alterations, it was present in $10.56 \%$ of the examined children, and hypoplasia was the most frequent type of enamel lesion (71.10\%) (Table 1).

Regarding dmf-t, it was 1.53 and dmf-s was 2.68. Table 3 shows the both averages according to the health district of Salvador-BA. The highest dmf-t index was observed in the Barra-Rio Vermelho district (1.83) and the lowest was in Liberdade (1.00) (no significant difference from the districts). Children examined in municipal public daycare centers also had a higher dmf-t index than those who were examined at the Family Health Units (dmf-t equal to 1.58 and 1.34 , respectively).

The percentage analysis of the components of dmf-t and dmf-s was performed. The decayed component was the most frequent in both indexes ( $93.46 \%$ and $88.80 \%$, respectively).

In the univariate analysis, looking forward to potential factors associated with early caries, it was detected that this condition affected more preschoolers aged 55 months or more $(\mathrm{p}<0.000)$, preschoolers examined in municipal public daycare centers $(\mathrm{p}=$ 0.041), those with the presence of dental biofilm ( $p<0.000)$, with white spot lesions $(p<0.000)$ and with enamel changes $(p=0.008)$ (Table 2).

Regarding the potential factors related to the enamel alterations, these were more frequently present in children aged 55 months or older $(p=0.050)$, in those who were examined in mu-

\begin{tabular}{|c|c|c|}
\hline Variables & $\mathbf{n}$ & $\%$ \\
\hline \multicolumn{3}{|l|}{ Location } \\
\hline Public health unity & 609 & 21.84 \\
\hline Public daycare center & 2179 & 78.16 \\
\hline \multicolumn{3}{|l|}{ Age } \\
\hline 36- 54 months & 1277 & 45.80 \\
\hline 55 or more months & 1511 & 54.20 \\
\hline \multicolumn{3}{|l|}{ Gender } \\
\hline Boys & 1419 & 50.90 \\
\hline Girls & 1369 & 49.10 \\
\hline \multicolumn{3}{|c|}{ Ethnic group/color of skin } \\
\hline White & 196 & 7.03 \\
\hline Brown/ Blcak & 2592 & 92.97 \\
\hline \multicolumn{3}{|c|}{ Incipient lesions of dental caries } \\
\hline No & 2510 & 90.03 \\
\hline Yes & 278 & 9.97 \\
\hline \multicolumn{3}{|l|}{ Dental caries } \\
\hline No & 1718 & 61.62 \\
\hline Yes & 1070 & 38.38 \\
\hline \multicolumn{3}{|l|}{ Dental biofilm } \\
\hline No & 1219 & 43.72 \\
\hline Yes & 1569 & 56.28 \\
\hline \multicolumn{3}{|l|}{ Dental calculus } \\
\hline No & 2652 & 95.12 \\
\hline Yes & 136 & 4.88 \\
\hline \multicolumn{3}{|l|}{ Enamel defects } \\
\hline No & 2491 & 89.44 \\
\hline Yes & 294 & 10.56 \\
\hline \multicolumn{3}{|c|}{$\begin{array}{l}\text { Types of development defects of } \\
\text { enamel }\end{array}$} \\
\hline Hipoplasy & 209 & 71.10 \\
\hline Opacity & 62 & 21.09 \\
\hline Fluorosis & 23 & 7.81 \\
\hline
\end{tabular}

Table 1: Distribution of sociodemographic variables and oral health conditions in children aged 3 to 5 years-old in Salvador- Bahia. Brazil,2018 ( $\mathrm{n}=2788)$.

nicipal public daycare centers $(\mathrm{p}=0.010)$ and who had dental caries $(p=0.008)$ (Table 3 and 4$)$.

\section{Discussion}

The findings of this epidemiological investigation in the city of Salvador-BA revealed that early caries was still a very common oral health problem among preschoolers, and that enamel changes also affect part of this population group, with an association between them. That is, children with enamel defects are more likely to de- 


\begin{tabular}{|l|c|c|c|c|}
\hline $\begin{array}{c}\text { Health Administrative } \\
\text { District }\end{array}$ & $\begin{array}{c}\mathbf{d m}- \\
\mathbf{f - t}\end{array}$ & $\mathbf{C I 9 5 \%}$ & $\begin{array}{c}\mathbf{d m}-\mathbf{f - s} \\
\mathbf{f}\end{array}$ & $\mathbf{C I 9 5 \%}$ \\
\hline Cajazeiras (n=221) & 1.68 & $1.32-2.04$ & 3.34 & $2.45-4.22$ \\
\hline Itapagipe (n=297) & 1.19 & $0.93-1.46$ & 2.32 & $1.70-2.96$ \\
\hline Cabula-Beirú (n=179) & 1.76 & $1.32-2.19$ & 2.88 & $2.05-3.71$ \\
\hline $\begin{array}{l}\text { Centro Histórico } \\
(\mathrm{n}=137)\end{array}$ & 1.50 & $0.99-2.00$ & 2.01 & $1.21-2.82$ \\
\hline Boca do Rio (n=302) & 1.62 & $1.31-1.92$ & 2.99 & $2.28-3.69$ \\
\hline Liberdade (n=161) & 1.00 & $0.70-1.31$ & 1.77 & $1.12 .-2.42$ \\
\hline Brotas (n=231) & 1.30 & $0.99-1.61$ & 1.98 & $1.41-2.55$ \\
\hline Itapuã (n= 280) & 1.77 & $1.43-2.11$ & 3.51 & $2.62-4.41$ \\
\hline São Caetano (n=374) & 1.64 & $1.36-1.92$ & 2.67 & $2.15-3.19$ \\
\hline $\begin{array}{l}\text { Barra-Rio Vermelho } \\
\text { (n=229) }\end{array}$ & 1.83 & $1.43-2.23$ & 3.24 & $2.33-4.15$ \\
\hline Pau da Lima (n=178) & 1.52 & $1.12-1.91$ & 2.33 & $1.61-3.06$ \\
\hline $\begin{array}{l}\text { Subúrbio Ferroviário } \\
\text { (n=199) }\end{array}$ & 1.37 & $0.98-1.76$ & 2.38 & $1.59-3.17$ \\
\hline Total & 1.53 & $1.43-1.63$ & 2.68 & $2.47-2.90$ \\
\hline
\end{tabular}

Table 2: Caries distribution (dmf-t and dmf-s) and confidence interval 95\% (CI 95\%) in children aged 3 to 5 years-old in Salvador, Bahia, Brazil by Health Administrative Disctrict. $2018(\mathrm{n}=2788)$. velop caries in the primary dentition.

In 2.788 children, $50.90 \%$ were male, unlike other surveys carried out with the same age group, when most of the sample consisted of girls $[1,17,18]$.

Regarding the age group of preschoolers, the average age of the children participating in the study was 54 months, as well as in the investigation by Nunes and Perosa[19], who investigated early caries in Avaré in the state of São Paulo. In the study conducted by Almeida et al.[1] also in the city of Salvador-BA with preschoolers, the average age was 42 months. Regarding the skin color of the children in this study, most were black (92.97\%), which also occurred in the investigation conducted by Almeida et al.[1] mentioned above, where the number of black children was 449 in 528 preschoolers (85.04\%).

In the assessed oral health problems, most of the children investigated did not have white spots lesions (90.03\%), however $38.38 \%$ of them had dental caries lesions in more advanced stages, according to the criteria diagnosis of dmf-t. This percentage was different from that found by Cangussu et al.[4] in the city of Salvador-BA. In a cohort study of 495 children aged 4 to 30 months

\begin{tabular}{|c|c|c|c|c|c|c|}
\hline \multirow{2}{*}{\multicolumn{2}{|c|}{ Sociodemographicvariables }} & \multicolumn{2}{|c|}{ Absence of dental caries } & \multicolumn{2}{|c|}{ Presence of dental caries } & \multirow[t]{2}{*}{ p-value* } \\
\hline & & $\mathbf{n}$ & $\%$ & $n$ & $\%$ & \\
\hline \multirow[t]{2}{*}{ Sex } & Boys & 876 & 61.73 & 543 & 38.27 & \multirow[t]{2}{*}{0.901} \\
\hline & Girls & 842 & 61.50 & 527 & 38.50 & \\
\hline \multirow[t]{2}{*}{ Age } & 36-54 months & 881 & 68.99 & 396 & 31.01 & \multirow[t]{2}{*}{0.000} \\
\hline & 55 months or more & 837 & 55.39 & 674 & 44.61 & \\
\hline \multirow[t]{2}{*}{ Ethnicgroup/color of skin } & White & 131 & 66.84 & 65 & 33.16 & \multirow[t]{2}{*}{0.119} \\
\hline & Brown/Blacks & 1587 & 61.23 & 1005 & 38.77 & \\
\hline \multirow[t]{2}{*}{ Location } & Public Health Unity & 397 & 65.19 & 212 & 34.81 & \multirow[t]{2}{*}{0.041} \\
\hline & Public daycare center & 1321 & 60.62 & 858 & 39.38 & \\
\hline \multicolumn{7}{|l|}{ Oral health conditions } \\
\hline \multirow[b]{2}{*}{ Dental biofilm } & No & 881 & 72.27 & 338 & 27.73 & \multirow[b]{2}{*}{0.000} \\
\hline & Yes & 837 & 53.35 & 732 & 46.65 & \\
\hline \multirow[t]{2}{*}{ Incipient dental caries } & No & 1605 & 63.94 & 905 & 36.06 & \multirow[t]{2}{*}{0.000} \\
\hline & Yes & 113 & 40.65 & 165 & 59.35 & \\
\hline \multirow[t]{2}{*}{ Enamel defects } & No & 1570 & 62.43 & 945 & 37.57 & \multirow[t]{2}{*}{0.008} \\
\hline & Yes & 148 & 54.21 & 125 & 45.79 & \\
\hline
\end{tabular}

Table 3: Prevalence distribution of dental caries by sociodemographic variables, location and others oral health conditions in children aged 3 to 5 years-old in Salvador, Bahia, Brazil, 2018 ( $n=2788$ ).

* Qui Square Pearson analyses. 


\begin{tabular}{|c|c|c|c|c|c|c|}
\hline \multirow{2}{*}{\multicolumn{2}{|c|}{ Sociodemographic variables }} & \multicolumn{2}{|c|}{ Absence of DDE } & \multicolumn{2}{|c|}{ Presence of DDE } & \multirow{3}{*}{$\begin{array}{c}\text { p-value* } \\
0.073\end{array}$} \\
\hline & & \multirow{2}{*}{$\begin{array}{c}\mathbf{n} \\
1266 \\
\end{array}$} & \multirow{2}{*}{\begin{tabular}{|c|} 
\% \\
89.22 \\
\end{tabular}} & \multirow{2}{*}{$\begin{array}{c}\mathbf{n} \\
153 \\
\end{array}$} & \multirow{2}{*}{\begin{tabular}{|c|}
$\%$ \\
10.78 \\
\end{tabular}} & \\
\hline Sex & Boys & & & & & \\
\hline & Girls & 1249 & 91.23 & 120 & 8.77 & \\
\hline \multirow[t]{2}{*}{ Age } & 36-54 months & 1174 & 91.93 & 103 & 8.07 & \multirow[t]{2}{*}{0.005} \\
\hline & 55 months or more & 1341 & 88.75 & 170 & 11.25 & \\
\hline \multirow[t]{2}{*}{ Ethnic group/color of skin } & White & 180 & 91.84 & 16 & 8.16 & \multirow[t]{2}{*}{0.426} \\
\hline & Brown/Blacks & 2335 & 90.08 & 257 & 9.92 & \\
\hline \multirow[t]{2}{*}{ Location } & Public Health Unity & 566 & 92.94 & 43 & 7.06 & \multirow[t]{2}{*}{0.010} \\
\hline & Public daycare center & 1949 & 89.44 & 230 & 10.56 & \\
\hline \multicolumn{7}{|l|}{ Oral health condition } \\
\hline \multirow[t]{2}{*}{ Dental caries } & No & 1570 & 91.39 & 148 & 8.61 & \multirow[t]{2}{*}{0.008} \\
\hline & Yes & 945 & 88.32 & 125 & 11.68 & \\
\hline
\end{tabular}

Table 4: Prevalence distribution of enamel defects by sociodemographic variables, location and dental caries in children aged 3 to 5 years-old in Salvador. Bahia. Brazil, 2018 ( $\mathrm{n}=2788)$.

* Qui Square Pearson analyses.

in public, private and philanthropic daycare centers, the latest authors noted that $91.9 \%$ of children were free of caries at the beginning of the survey. Nóbrega et al.[20] in the city of Teresina, in the state of Piauí, found a prevalence of caries of $50.20 \%$ among the 566 children examined, all of whom were 60 months old. In the investigation by Almeida et al.[7] the prevalence of early caries in Salvador was $49.6 \%$, while SB BRASIL 2010 revealed a prevalence of $50.4 \%$ of the same condition among children aged 5 years [5]. It should be noted that the percentage of children free of caries is always lower in the Northeast when compared to those in the South and Southeast of Brazil[5].

In the present study, more than half of the children (56.20\%) had dental biofilm, however most of them did not have calculus (95.12\%). Biral et al.[21] observed an even greater occurrence among the examined preschoolers in the city of São Paulo-SP: $72.37 \%$ of the children analyzed presented biofilm, which is a determining factor for the occurrence of caries and is directly related to inadequate oral hygiene habits, who at this stage of life are completely dependent on the capacity of family care.

The dmf-t index found here was 1.53. This result was lower than that observed for children aged 5 years of age in the last national oral health survey [5], in which the dmf-t was equal to 1.70 and among children in the Northeast this index proved to be highest: 3.94, reflecting health inequalities also in this population group.

The health district of Salvador-BA that presented the best condition in relation to severity of dental caries was Liberdade (dmf-t $=1.00$ ) and the worst condition was found in Barra-Rio Vermelho $(\mathrm{dmf}-\mathrm{t}=1.83)$. This inequality needs to be better investigated and considered for the planning of local health actions, aimed at preventing and controlling this problem. It is worth clarifying that goal number 1 of the oral health conditions of the World Health Organization (WHO) predicts that $50 \%$ of children at 05 years of age should be free of caries in the year 2000 [22], which was achieved in capital of Bahia in 2018. However, the need for restorative treatment is a reality among children in the country, as was also observed by this research, where almost $90 \%$ of the teeth affected by caries needed treatment. This percentage is similar to the findings of other epidemiological investigations in this age group [5,7].

According to Dorri et al.[23] dental caries is one of the most prevalent diseases in childhood and can be preventable. Several factors are associated with the development of early caries in childhood; the most cited in the literature are past caries experience, enamel defects, dental biofilm, diet, mother's education and family income [24].

In compliance with the analyses presented here of the potential associated factors related to caries, the older age of the children was associated with the development of this oral problem. For Ortiz et al.[25] the greater occurrence of caries in older children is due to the fact that they already have more teeth in the oral cavity with more time of exposure to risk factors.

The presence of children in daycare centers may also have contributed to the appearance of caries in preschoolers, since the children evaluated in these institutions had a higher prevalence of this disease than the children evaluated in health units in this same age group. It is possible that the oral condition of children in health units was more favorable due to the selection bias, since their 
families were looking for a health service, which shows the parents' attentive care with aspects of the child's health, a fact which may be related to better oral hygiene conditions, diet, etc. On the other hand, it is essential to recognize that the activities developed in municipal public daycare centers can lead to the adoption of healthier family habits of hygiene and food, which contributes to better oral health standards, according to the findings of the study by Biral et al.[21] in the city of São Paulo-SP.

With regard to changes in tooth enamel, it is highlighted that $10.56 \%$ of the children examined had some alteration, with enamel hypoplasia being the most frequent among them, as occurred in the investigation by Barbosa et al.[2] in São José dos Campos-SP. Hoffmann et al.[26] in Indaiatuba-SP, also evaluated these changes in the primary dentition and found that the prevalence of hypoplasia was higher $(\mathrm{p}<0.05)$ in the group of children with caries experience ( $\mathrm{dmf}-\mathrm{t}>0)$ than the group without caries experience. As believed by Ruschel et al.[27] among the enamel defects mentioned in this study, hypoplasia is the one most easily diagnosed because it is an incomplete or defective formation of tooth enamel, which can vary from white spots to tooth discoloration, varying from yellow to dark brown, and may be predisposed to dental caries.

In 2016, Massignan et al.[28] assessed the prevalence of enamel development defects in primary dentition and its relationship with dental caries in young children in Florianópolis-SC. The study pointed out that the prevalence of dental hypoplasia was $6.1 \%$ and that primary teeth with enamel hypoplasia were more likely to develop caries lesions, when compared to teeth without the enamel defect, as was verified in this study. Other epidemiological investigations have also indicated that hypoplastic teeth are more susceptible to the presence and evolution of carious lesions [26,29]. For Seow [13] this is due to the presence of changes in the anatomy of the dental enamel due to hypoplasia, for example. The altered anatomy of the enamel can cause greater accumulation of dental biofilm, which in turn can lead to early caries.

The positive association of the enamel alterations with the children's age also drew attention, with this condition being more common among older children. This finding may have occurred due to the eruption process of older children having ended, enabling a more accurate diagnosis of the disease in this group. Tourino et al.[11] did not observe this relationship between the 118 children examined in Ijaci-MG.

Health surveillance presupposes an epidemiological approach as a strategy for controlling the most prevalent diseases in populations. Dental caries still remains quite present among children in the preschool age group of the city of Salvador-BA, as this research with a population approach revealed, which represents one of the advantages of this study in relation to other research already carried out. We must also emphasize that this study clarifies for the first time the magnitude of the enamel changes in a representative sample of the capital of Bahia. However, the findings of the exploratory analyzes must be analysed with caution, considering the type of study carried out (cross-section), which does not guarantee the temporal advance of the potential risk factors. Municipal public policies must recognize the extent and severity of oral disorders among children of such young age, as demonstrated here, and propose preventive and surgical-restorative actions that are more equitable and effective for them.

\section{Conclusion}

This study showed that the prevalence of early caries was $38.38 \%$ and enamel alteration $10.56 \%$, hypoplasia being the most common enamel defect; the dmf-t was equal to 1.53. Caries was associated with the child's older age (55 months or more), with the presence of white spots, dental biofilm and enamel changes ( $p$ $<0.05$ ). The enamel changes were associated with the older age of the children (55 months or more) and the presence of caries. Children who were examined at public day care centers had more oral problems than those who were examined at Family Health Units ( $p$ $<0.05$ ).

\section{Bibliography}

1. Almeida TF., et al. "Occurrence of dental caries and associated factors in children from 24 to 60 months living in areas covered by the Family Health Program, Salvador - BA, 2008". Revista de Odontologia da UNESP 39.6 (2010): 355-362.

2. Barbosa DML., et al. "Prevalence of enamel hypoplasia in primary teeth of prematurely-born children". Revista de Odontologia da UNESP 37.3 (2008): 261-265.

3. Sakaryali D., et al. "Evaluation of the impact of early childhood caries, traumatic dental injury, and malocclusion on oral health - related quality of life for Turkish preschool children and families". Nigerian Journal of Clinical Practice 22.6 (2019): 817-823.

4. Cangussu MC., et al. "Risk factors for dental caries in children in early childhood, Salvador-BA". Brazilian Journal of Maternal and Child Health 16.1 (2016): 57-64.

5. Brazil. Ministry of Health. "SB Brasil 2010: National Oral Health Survey: main results”. Brasília - DF: Ministry of Health (2012).

6. Brazil. Ministry of Health. "Oral Health Conditions of the Brazilian Population 2002-2003: Main Results”. Brasília - DF: Ministry of Health (2004). 
7. Almeida TF., et al. "The dental health of preschool-aged children resident in areas covered by the Family Health Program, in the city of Salvador, in the State of Bahia, Brazil". Revista Brasileira Saúde Materno-Infantil 9.3 (2009): 247-252.

8. Municipal Health Secretariat of Salvador-BA (SMS). "Oral Health Conditions of the Population of the Municipality of Salvador". Salvador-BA: Municipal Health Secretariat of Salvador-BA (2015).

9. Pascon T., et al. "Prenatal exposure to gestational diabetes mellitus increases developmental defects in the enamel of offspring". PLoS ONE 14.2 (2019): e211771.

10. Faria PC., et al. "Perinatal factors associated with developmental defects of enamel in primary teeth: a case-control study". Brazilian Oral Research 27.4 (2013): 363-368.

11. Tourino LFP., et al. "Prevalence and factors associated with enamel defects among preschool children from a southeastern city in Brazil". Ciência \& Saúde Coletiva 23.5 (2018): $1667-$ 1674.

12. Salas MMS., et al. "Non-fluorotic enamel defects in children: clinical and epidemiological aspects". RFO UPF 21.2 (2016): 251-259.

13. Seow WK. "Developmental defects of enamel and dentine: challenges for basic science research and clinical management". Australian Dental Journal 59.1 (2014): 143-154.

14. International Dental Federation (FDI). Commission on Oral Health, Research and Epidemiology. "Report of an FDI Working Group. A review of the developmental defects of enamel index (DDE Index)". International Dental Journal 42 (1992): 411-426.

15. Microsoft Office Excel, Excel 14.0 (Office 365): Microsoft Corporation, 2016. Set of programs. 1CD-ROM (2016).

16. STATA. Data Analysis and Statistical Software: Release 14. [S.I]: Stata Corp LP (2015).

17. Firmino RT., et al. "Impact of oral health problems on the quality of life of preschool children: a case - control study". International Journal of Paediatric Dentistry 26 (2016): 242-249.

18. Guedes RS., et al. "Assessing individual and neighborhood social factors in child oral health-related quality of life: a multilevel analysis". Quality of Life Research 23.9 (2014): 25212530 .

19. Nunes VH and Perosa GB. "Dental caries in 5-year-old children: sociodemographic factors, locus of control and parental attitudes". Ciência \& Saúde Coletiva22.1 (2017): 191-200.

20. Nóbrega $A V$., et al. "Impact of dental caries on the quality of life of preschoolers measured by the PedsQL questionnaire". Ciência \& Saúde Coletiva 24.11 (2019): 4021-4041.

21. Biral AM., et al. "Dental caries and eating practices among children in daycare centers in the city of São Paulo". Revista de Nutrição 26.1 (2013): 37-48.

22. Federation Dentaire Internacionale. Global goals for oral health in the year 2000". The International Dental Journal 32.1 (1982): 74-77.

23. Dorri M., et al. "Atraumatic restorative treatment versus conventional restorative treatment for managing dental caries". Cochrane Database of Systematic Reviews (2017): 12.

24. Lopes LM., et al. "Indicators and risk factors for dental caries in children in Brazil - a literature review". RFO UPF 19 (2014): 245-251.

25. Ortiz FR., et al. "Factors associated with Oral Health-Related Quality of Life of preschool children in Southern Brazil". Revista Gaúcha de Odontologia 64.3 (2016): 256-262.

26. Hoffmann RHS., et al. "Prevalence of enamel defects and the relationship to dental caries in deciduous and permanent dentition in Indaiatuba, São Paulo, Brazil". Cadernos de Saúde Pública 23.2 (2007): 435-444.

27. Ruschel HC., et al. "Hypoplasia and hypocalcification of first permanent molars". Revista da ABO Nacional 14.2 (2006): 8994.

28. Massignan C., et al. "Prevalence of enamel defects and association with dental caries in preschool children". European Archives of Paediatric Dentistry 17.6 (2016): 461-466.

29. Ribas AO and Czlusniak GD. "Dental enamel anomalies: etiology, diagnosis and treatment”. UEPG Biol. Health Sci.1 (2009):

\section{Assets from publication with us}

- Prompt Acknowledgement after receiving the article

- Thorough Double blinded peer review

- Rapid Publication

- Issue of Publication Certificate

- High visibility of your Published work

Website: www.actascientific.com/

Submit Article: www.actascientific.com/submission.php

Email us: editor@actascientific.com

Contact us: +919182824667 